\title{
Social inequalities in old age. A life of inequality
}

Public health research has provided us with information that despite its apparent logic is systematically ignored by politicians. It also goes beyond the scope of health professionals, as the social determinants of health can be much more powerful than and extend far beyond biological determinants ${ }^{1}$. Such social conditioners can be more significant than biological conditioners in the context of disease, and also determine and are a key part of healthy behavior. We live in a world of individualized health problems. Health professionals and campaigns and the vox populi focus on purely individual messages such as don't smoke, go for a walk and take your medication, as though all our health-related behaviors were decided upon consciously and individually, and ignoring the fact that smoking, walking or taking medication can be linked to factors as diverse as family or work stress, poor education, inadequate infrastructure, little time or lack of money.

The social determinants of health condition us from birth to death, from the pollution of the neighborhood in which we are born (usually greater in areas where those of a lower social status live), which conditions our neuronal development, to the house where we die, where the lack of an elevator, heating or other facilities can condition and reduce our physical and mental health.

The existence of the social determinants of health is nothing new, with Rudolf Carl Virchow establishing their importance in 1847 in his statement that "politics is nothing but medicine at a larger scale"2.

Among people aged over 65 in Europe today, those from disadvantaged social positions suffer greater limitations in activities of daily living than people from more favored social classes ${ }^{3}$, and diabetes and diabetes related-deaths are more prevalent among those from disadvantaged social positions than in people with a more favored social status ${ }^{4,5}$. This can be due to unequal access to healthy foods, social barriers to access to physical exercise, or inequalities in the likelihood of correct treatment. When considering those over 65, one must inevitably think of people who have suffered exposure to social inequality throughout their lives. A common mistake is to think that social inequality in health is synonymous with poverty. This myth was rejected by the Whitehall ${ }^{6}$ study, where the existence of a hierarchy based on a social gradient was found in mortality from heart disease among civil servants. Deaths among those with a higher position in the organization were less prevalent than among those of a lower rank, which in turn were less frequent than among those of an even lower rank. The results of this study showed that even among those who already had the basic necessities of life ensured, social position played a key role in the risk of dying or suffering more diseases than others.

Yet if we have known about the social determinants of health for so long, why do we continue to focus on the individual aspects of health? Political impetus is required to change this situation, together with the involvement of society as a whole at all levels. Achieving this is made difficult as the individualist discourse, 
which does not consider the causes of the causes, has predominated for many years. In this sense, it is easier to think that a person who drinks alcohol does so because he/she wants to, than to think that it is the urban environment and the continuous exposure to alcohol that ends up conditioning their behavior (such as advertising, offers, discounts, promotions and shop windows). Society has labeled health behaviors as lifestyles of individual choice, forgetting that these behaviors are often conditioned by social determinants. Manresa Faculty of Health Sciences. Manresa, Spain.

\section{REFERENCES}

1. Cofiño Fernández R. Tú código postal es más importante para tu salud que tu código genético. Aten Primaria. 2013;45(3):127-8.

2. Virchow RC. Report on the typhus epidemic in Upper Silesia. 1848. Am J Public Health. 2006;96(12):2102-5.

3. Espelt A, Font-Ribera L, Rodriguez-Sanz M, Artazcoz L, Ferrando J, Plaza A, et al. Disability among older people in a southern European city in 2006: trends in gender and socioeconomic inequalities. J Womens Health. 2010;19(5):927-33.

4. Espelt A, Borrell C, Roskam AJ, Rodriguez-Sanz M, Stirbu I, Dalmau-Bueno A, et al. Socioeconomic inequalities in diabetes mellitus across Europe at the beginning of the 21st century. Diabetologia. 2008;51(11):1971-9.

5. Espelt A, Arriola L, Borrell C, Larrañaga I, Sandín M, Escolar-Pujolar A. Socioeconomic position and type 2 diabetes mellitus in Europe 1999-2009: a panorama of inequalities. Curr Diabetes Rev. 2011;7(3):148-58.

6. Marmot MG, Smith GD, Stansfeld S, Patel C, North F, Head J, et al. Health inequalities among British civil servants: the Whitehall II study. Lancet. 1991;337(8754):1387-93. 